\title{
Produtividade e características biométricas do capim-braquiária em sistema silvipastoril
}

\author{
Cristiam Bosi(1), José Ricardo Macedo Pezzopane ${ }^{(2)}$, Paulo Cesar Sentelhas ${ }^{(1)}$, \\ Patrícia Menezes Santos ${ }^{(2)}$ e Maria Luiza Franceschi Nicodemo(2)
}

(1)Universidade de São Paulo, Escola Superior de Agricultura Luiz de Queiroz, Avenida Pádua Dias, № 11, CEP 13418900 Piracicaba,
SP, Brasil. E-mail: cristiambosi@yahoo.com.br, pcsentel.esalq@usp.br (2)Embrapa Pecuária Sudeste, Rodovia Washington Luiz, Km 234,
CEP 13560970 São Carlos, SP, Brasil. E-mail: jose.pezzopane@embrapa.br, patricia.santos@embrapa.br, marialuiza.nicodemo@embrapa.br

Resumo - O objetivo deste trabalho foi avaliar a produtividade e as características biométricas do capimbraquiária (Urochloa decumbens) sob pastejo, em sistema silvipastoril. Avaliou-se um sistema com árvores nativas de interesse comercial, plantadas em renques, no sentido norte-sul, espaçados por $17 \mathrm{~m}$. Utilizou-se o delineamento experimental de blocos ao acaso, com quatro repetições e parcelas subdivididas, tendo-se avaliado o ciclo de rebrota da forragem nas parcelas, e a distância desta em relação aos renques, nas subparcelas. Sete ciclos de rebrota foram avaliados, em quatro distâncias dos renques: a 2 e a $6 \mathrm{~m}$ do renque leste, e a 2 e a $6 \mathrm{~m}$ do renque oeste. Quantificou-se a produtividade de matéria seca, o índice de área foliar (IAF), a área foliar específica (AFE) e a altura das plantas. A produtividade de forragem, nos dois primeiros ciclos, e o IAF, no segundo e no terceiro ciclo, diminuiram com níveis de sombra acima de 39 e $40 \%$, respectivamente. Já a altura de plantas aumentou com sombreamentos superiores a 53\%, nos quatro primeiros ciclos; o que também ocorreu com a AFE, com sombreamento superior a $66 \%$, nos três primeiros ciclos.

Termos para indexação: Urochloa decumbens, árvores nativas, deficit hídrico, radiação solar, sistemas agroflorestais, sombreamento.

\section{Productivity and biometric characteristics of signal grass in a silvopastural system}

\begin{abstract}
The objective of this work was to evaluate the productivity and biometric characteristics of signal grass (Urochloa decumbens) under grazing, in a silvopastural system. A system with native trees of commercial interest, planted in a set of rows with north-south orientation, with $17 \mathrm{~m}$ spacing was evaluated. A randomized complete block design with four replicates was carried out in a split-plot arrangement, with forage grass regrowth cycles evaluated in the plots and distances from trees in the subplots. Seven regrowth cycles were evaluated at four distances of the set of tree rows: at 2 and $6 \mathrm{~m}$ from trees at east, and at 2 and $6 \mathrm{~m}$ from trees at west. Dry matter productivity, leaf area index (LAI), specific leaf area (SLA), and plant height were measured. Forage productivity in the first two cycles and LAI in the second and third cycles reduced with shading levels higher than 39 and $40 \%$, respectively. However, plant height increased with shadings greater than $53 \%$, in the first four cycles, and SLA with shadings greater than $66 \%$, in the first three cycles.
\end{abstract}

Index terms: Urochloa decumbens, native trees, water deficit, solar radiation, agroforestry systems, shading.

\section{Introdução}

Os sistemas silvipastoris (SSPs) são uma modalidade dos sistemas agroflorestais com animais, plantas forrageiras e árvores em uma mesma área. O manejo desses sistemas é bem mais complexo do que o de pastagens exclusivas ou de florestas plantadas, e deve ser rigorosamente planejado em razão da necessidade da manutenção do equilíbrio entre os seus componentes e do grande número de interações possíveis entre eles e o ambiente (Bernardino \& Garcia, 2009).
Dos fatores climáticos que influenciam a produção de biomassa de espécies forrageiras, destacam-se: a radiação solar, a temperatura do ar e a disponibilidade hídrica (Zanine, 2005). Em sistemas silvipastoris, a disponibilidade de energia radiante sob as copas assume papel ainda mais preponderante para a produção das forrageiras, por causa do sombreamento exercido pelas árvores.

A tolerância da pastagem ao sombreamento depende de sua habilidade em se adaptar, morfológica ou fisiologicamente, a um nível específico de luminosidade 
(Dias-Filho, 2000). Em SSP com disposição das árvores na forma linear ou em renques, espera-se que a influência das árvores sobre a pastagem seja maior em áreas mais próximas aos troncos; no entanto, os efeitos do sombreamento podem alcançar áreas localizadas além da projeção das copas (Dias et al., 2007). Vários trabalhos têm sido realizados nos últimos anos com o objetivo de identificar e explicar os efeitos da presença de árvores sobre o pasto em SSPs (Paciullo et al., 2011; Carrilho et al., 2012; Gómez et al., 2013). Paciullo et al. (2011) estudaram a Urochloa decumbens (syn Brachiaria decumbens) em sistema agrossilvipastoril arborizado com renques de Eucalyptus grandis e Acacia mangium, dispostos no sentido norte-sul, e constataram que a produtividade de forragem aumentou, conforme diminuia o sombreamento, até à distância de $9 \mathrm{~m}$ em relação às árvores; porém, nas distâncias de 12 e 15 m, eles relataram redução no rendimento, o que mostra que, $U$. decumbens pode produzir mais em níveis moderados de sombra do que em ambientes a pleno sol, em que estresses ambientais, como o deficit hídrico, podem ser maiores. Carrilho et al. (2012) avaliaram pastagem de $U$. decumbens sob três níveis de sombreamento artificial $(0,30$ e 50\%) e concluíram que a produção de biomassa e o número de plantas por hectare não foram afetados pelos tratamentos; porém, nos locais sombreados, as plantas obtiveram menor percentagem de matéria seca e, a $50 \%$ de sombreamento, maior área foliar específica.

Gómez et al. (2013) estudaram U. decumbens sob três níveis de sombreamento (70, 50 e $0 \%)$, na Venezuela, e constataram que a produtividade final da pastagem diminuiu $34 \%$ com o sombreamento de $50 \%$, e $57 \%$ com $70 \%$ de sombreamento. Além disso, o sombreamento aumentou a área foliar específica em até $46 \%$. Assim, esses autores concluíram que $U$. decumbens apresenta alta plasticidade ao sombreamento, o que explica o sucesso de sua utilização em SSPs.

A orientação dos renques de árvores no sentido nortesul, em regiões tropicais, aumenta o sombreamento nas entrelinhas; porém, em muitos casos, esta orientação é utilizada por recomendação de plantio em curvas de nível, em locais com maior declividade do terreno (Paciullo et al., 2011). Além disso, são poucos os trabalhos que tratam da influência da arborização de pastagens de $U$. decumbens com espécies nativas do Cerrado e da Mata Atlântica, o que torna relevante a quantificação de sua influência sobre $U$. decumbens.
O objetivo deste trabalho foi avaliar o efeito do arranjo de árvores nativas, em renques no sentido norte-sul, sobre a produtividade e as características biométricas do capim-braquiária, sob pastejo, em sistema silvipastoril.

\section{Material e Métodos}

$\mathrm{O}$ experimento foi realizado em área experimental com sistema silvipastoril, implantado em dezembro de 2007, pertencente à Embrapa Pecuária Sudeste, no

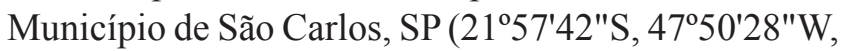
à altitude de $860 \mathrm{~m}$ ). O clima na região é do tipo Cwa, da classificação de Köppen (tropical de altitude), caracterizado por verão quente e úmido e inverno seco. A área foi composta por pastagem da espécie Urochloa decumbens (syn. Brachiaria decumbens), estabelecida há mais de 20 anos em manejo extensivo que, em 2007, foi arborizada nas linhas centrais com as seguintes espécies nativas de interesse econômico: angico-branco [Anadenanthera colubrina (Vell.) Brenan, Fabaceae], canafístula [Peltophorum dubium (Spreng.) Taub., Fabaceae], ipê-felpudo [Zeyheria tuberculosa (Vell.) Bureau, Bignoniaceae], jequitibábranco [Cariniana estrellensis (Raddi) Kuntze, Lecythidaceae] e pau-jacaré [Piptadenia gonoacantha (Mart.) J.F.Macbr., Fabaceae]. Para tutoramento dessas espécies, foram plantadas duas linhas marginais de mutambo (Guazuma ulmifolia Lamarck, Malvaceae) e de capixingui [Croton floribundus Spreng., Euphorbiaceae] mesclados. Em novembro de 2012, as espécies de interesse econômico apresentavam a altura média de 3,2 m, e as espécies tutoras, de 7,1 m. As linhas laterais foram tomadas como referência para a determinação das distâncias de avaliação da forragem.

Nos renques, os espaçamentos entre árvores na linha e entre a linha central e as linhas marginais foi de $2,5 \mathrm{~m}$, o que totalizou 550 árvores por hectare. As linhas foram dispostas conforme a declividade do terreno, em sentido próximo ao norte-sul, com leve tendência para o nordeste-sudoeste. Os renques foram formados pelo conjunto de uma linha central e duas linhas laterais e o espaçamento entre eles foi de $17 \mathrm{~m}$ (Figura 1). A área entre os renques foi usada para o pastejo dos bovinos em piquetes de $U$. decumbens.

Os renques foram cercados com cerca elétrica, tendo-se deixado uma faixa útil de pastagem de $15 \mathrm{~m}$ de largura. Nesta área, foram mantidos bovinos da raça

Pesq. agropec. bras., Brasília, v.49, n.6, p.449-456, jun. 2014 DOI: 10.1590/S0100-204X2014000600006 
Canchim, em pastejo rotacionado, com período de ocupação em cada piquete de sete dias e período de descanso de 35 dias. A taxa de lotação dos piquetes foi variável, tendo sido ajustada conforme a oferta de forragem, de forma a deixar uma altura para saída dos animais de aproximadamente $0,20 \mathrm{~m}$.

Foram avaliados sete ciclos de rebrota, em um piquete do SSP com $270 \mathrm{~m}$ de comprimento e $15 \mathrm{~m}$ de largura, em quatro distâncias de avaliação: a $2 \mathrm{~m}$ do renque leste $(2 \mathrm{~mL}) ;$ a $6 \mathrm{~m}$ do renque leste $(6 \mathrm{~mL}) ;$ a $6 \mathrm{~m}$ do renque oeste $(6 \mathrm{mO})$; e a 2 metros do renque oeste (2 mO) (Figura 1). O monitoramento, em cada ciclo, foi realizado logo após a saída dos animais da área na situação de planta pós-pastejo - e aproximadamente 35 dias depois - coleta pré-pastejo.

Os ciclos de rebrota ocorreram nas seguintes datas: ciclo 1 , de 23/11 a 27/12/2012; ciclo 2 , de $3 / 1$ a 7/2/2013; ciclo 3, de 14/2 a 20/3/2013; ciclo 4, de 28/3 a 2/5/2013; ciclo 5, de $9 / 5$ a 13/6/2013; ciclo 6 , de $11 / 7$ a 14/8/2013; e ciclo 7, de 22/8 a 25/9/2013.

Em cada coleta de forragem, foram retiradas duas amostras por ponto, em uma área de $0,25 \mathrm{~m}^{2}$, o que totalizou 32 amostras, para a quantificação da produção de matéria verde (MV) e matéria seca (MS) acima dos 0,10 m. Posteriormente, duas amostras correspondentes a cada ponto foram misturadas, tendo-se retirado duas subamostras: uma destinada para as avaliações morfológicas - determinação da proporção folha/colmo/material morto e mensuração da área foliar com uso de um integrador de área foliar, modelo LI-3100C (Li-Cor, Lincoln, NE, EUA), tendose calculado o IAF e a AFE (razão entre área foliar e massa de matéria seca de folha); e a outra destinada à determinação da MS total. Para a determinação da MS total, o material foi seco em estufa, com circulação de ar forçada, a $60^{\circ} \mathrm{C}$.

Além disso, foram coletados dados de altura de planta, em três pontos dentro da área útil de cada amostra. A altura de resíduo para o corte foi de $0,10 \mathrm{~m}$, em relação à superfície do solo, ou seja, abaixo da altura média de forragem definida para o momento da saída dos animais, que foi de $0,20 \mathrm{~m}$. Essa altura de resíduo foi fixada com o objetivo de evitar a subestimativa da massa de forragem pastejada, pois a desuniformidade, comum em condições de pastejo, provoca a ocorrência de locais com alturas de saída menores do que a média. O material morto (MM) presente na coleta póspastejo não foi descontado para o cálculo do acúmulo de MS do ciclo. Como ele é perdido para o solo, foi necessário efetuar uma correção da produtividade de

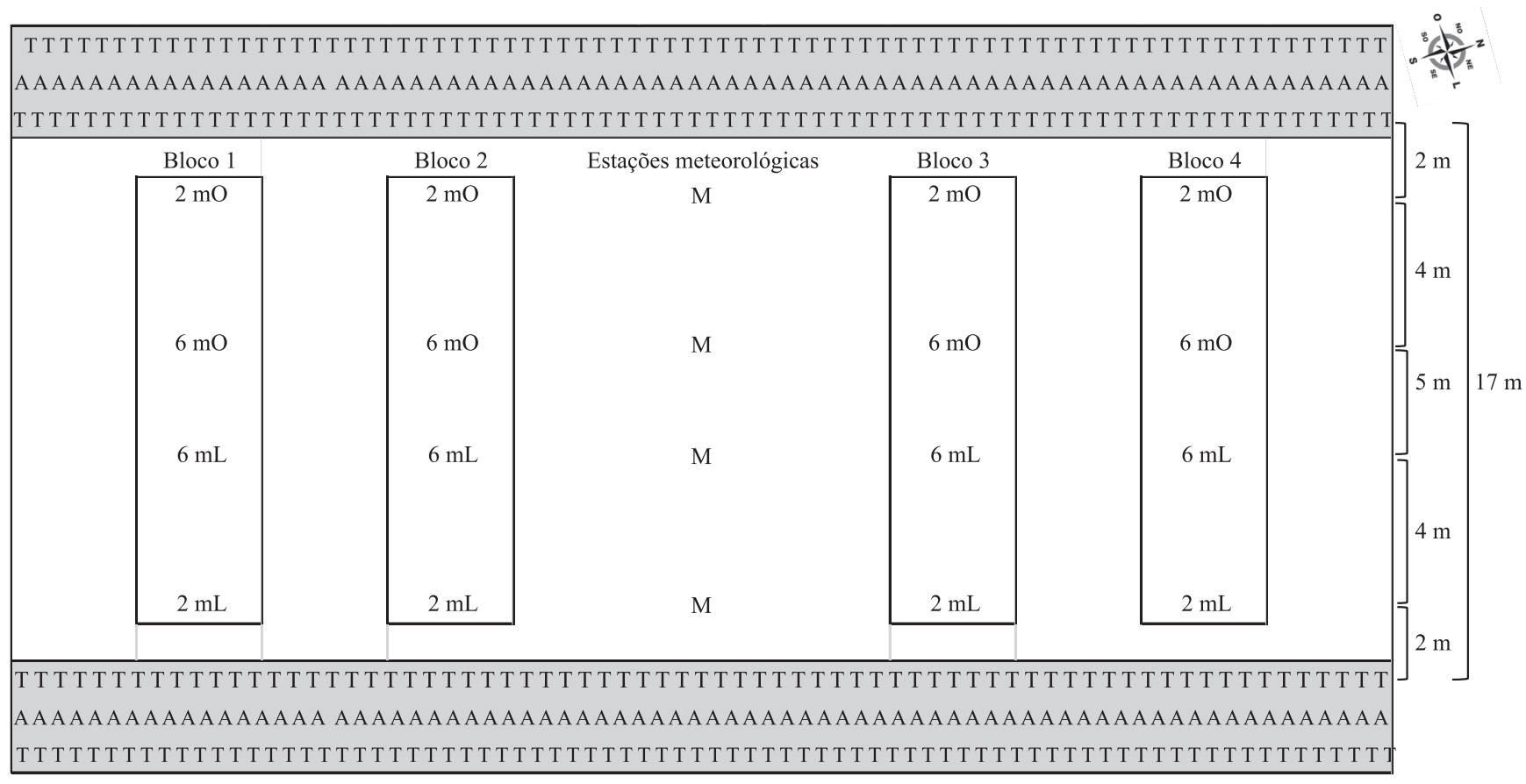

Figura 1. Croqui da área experimental, com os pontos de coleta de dados da forragem (Urochloa decumbens, a $2 \mathrm{~mL}, 6 \mathrm{~mL}, 6 \mathrm{mO}$ e $2 \mathrm{mO}$ ) a disposição das estações meteorológicas (M) e das árvores na área experimental. A, árvores de interesse econômico; e T, árvores tutoras. 
MS ( $\mathrm{MS}_{\text {corr }}$ ) pelo desaparecimento de MM. Assim, a coleta pós-pastejo foi tomada como referência inicial para determinação do acúmulo de forragem posterior, e a diferença de massa de matéria seca de MM dessa coleta para a da coleta pré-pastejo foi subtraída da produtividade de MS acumulada no ciclo $\left(\mathrm{MS}_{\mathrm{ac}}\right)$, conforme a equação: $\mathrm{MS}_{\mathrm{corr}}=\left[\mathrm{MS}_{\mathrm{ac}}-\left(\mathrm{MM}_{\text {pós-pastejo }}\right.\right.$ $\left.\left.\mathrm{MM}_{\text {pré-pastejo }}\right)\right]$.

A caracterização das condições hídricas do período foi obtida com o balanço hídrico sequencial (Thornthwaite \& Mather, 1955), na escala quinquidial, em que a evapotranspiração de referência (ETo) foi calculada segundo a equação de Penman-Monteith, descrita por Allen et al. (1998), com dados obtidos de uma estação meteorológica situada a cerca de $500 \mathrm{~m}$ do experimento (Figura 2).

Para a quantificação da incidência de radiação solar e da temperatura do ar, foram instaladas quatro estações meteorológicas com piranômetros, modelo Li-200X (Li-Cor, Lincoln, NE, EUA) e sensores de temperatura e umidade do ar, modelo HMP50 (Vaisala, Helsinki, Finlândia), à altura de $0,60 \mathrm{~m}$ em relação ao solo, no interior da área experimental (Figura 1). Os sensores foram conectados a um sistema automático de coleta e armazenamento de dados, modelo CR1000 (Campbell Scientific, Logan, UT, EUA), programado para efetuar leituras a cada $10 \mathrm{~s}$ e fornecer valores médios a cada $10 \mathrm{~min}$, além de dados horários e diários. Por meio dos dados de incidência de radiação solar global, em cada posição do SSP, comparados aos dados externos, determinouse a percentagem de sombreamento nas diferentes épocas (Tabela 1).

Para análise estatística, utilizou-se o delineamento experimental de blocos completos ao acaso, em arranjo de parcelas subdivididas, em que a parcela foi o ciclo de rebrota e a subparcela, a distância em relação aos renques, com quatro repetições. Foram analisados os dados biométricos e de produtividade da $U$. decumbens, por meio do procedimento GLM do SAS (SAS Institute, Cary, NC, EUA). Os efeitos fixos significativos foram comparados, pelo teste Tukey, a 5\% de significância. A correlação entre os dados biométricos e de produtividade da pastagem e as variáveis micrometeorológicas observadas no interior do SSP, nas épocas seca e chuvosa, foi determinada por meio do coeficiente de correlação de Pearson (r).
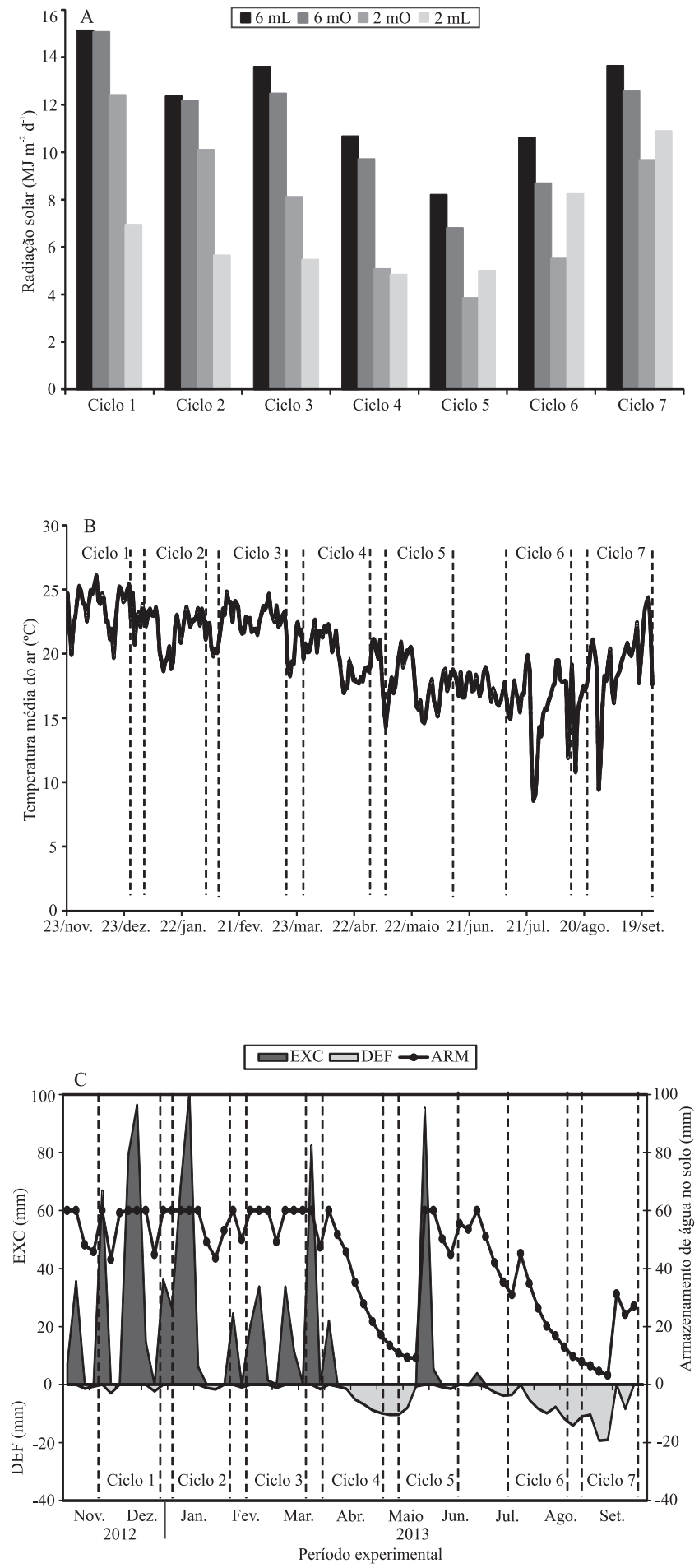

Figura 2. Dinâmica dos fatores ambientais durante o período experimental, nas posições a $6 \mathrm{~m}$ do renque leste $(6 \mathrm{~mL})$, a $6 \mathrm{~m}$ do renque oeste $(6 \mathrm{mO})$, a $2 \mathrm{~m}$ do renque oeste $(2 \mathrm{mO})$ e a $2 \mathrm{~m}$ do renque leste $(2 \mathrm{~mL})$, em sistema silvipastoril. $\mathrm{A}$, radiação solar média; $\mathrm{B}$, temperatura média do ar; $\mathrm{C}$, armazenamento de água no solo (ARM); DEF, deficiência hídrica; e EXC, excedente hídrico. 


\section{Resultados e Discussão}

A produtividade da forragem diferiu significativamente conforme as distâncias, apenas nos dois primeiros ciclos. No ciclo 1, a posição $6 \mathrm{~mL}$, que apresentou $1.745 \mathrm{~kg} \mathrm{ha}^{-1}$ de MS (Figura 3), foi mais produtiva do que a posição $2 \mathrm{mO}$, em decorrência do maior sombreamento nessa última (39\%) em comparação à primeira (25\%) (Tabela 1$)$. No ciclo 2 , a posição $6 \mathrm{~mL}$ também apresentou maior produtividade do que as demais posições, tendo atingido $1.500 \mathrm{~kg} \mathrm{ha}^{-1}$ de MS, aproximadamente $740 \mathrm{~kg} \mathrm{ha}^{-1}$ a mais do que na posição $2 \mathrm{mO}$. Esses resultados são indicativos de que a produtividade da forragem foi afetada negativamente em sombreamentos maiores que 39\%. Paciullo et al. (2011) observaram redução da produção de forragem de $U$. decumbens a partir dos $25 \%$ de sombreamento.

A posição $2 \mathrm{~mL}$ foi desconsiderada na análise do ciclo 2, pois houve subpastejo nessa posição, o que acarretou menor acúmulo de forragem no período de descanso. Isso ocorreu em decorrência da taxa de lotação insuficiente nesse ciclo. No ciclo 3 , não houve diferença estatística entre as posições, o que pode ser

Tabela 1. Níveis de sombreamento (\%) exercidos pelas árvores nas posições a $6 \mathrm{~m}$ do renque leste $(6 \mathrm{~mL})$, a $6 \mathrm{~m}$ do renque oeste $(6 \mathrm{mO})$, a $2 \mathrm{~m}$ do renque oeste $(2 \mathrm{mO})$ e a $2 \mathrm{~m}$ do renque leste $(2 \mathrm{~mL})$, em cada ciclo de crescimento da pastagem de Urochloa decumbens, em sistema silvipastoril.

\begin{tabular}{lcccc}
\hline Ciclo & \multicolumn{4}{c}{ Posição } \\
\cline { 2 - 5 } & $6 \mathrm{~mL}$ & $6 \mathrm{mO}$ & $2 \mathrm{mO}$ & $2 \mathrm{~mL}$ \\
\hline 1 & 25 & 25 & 39 & 66 \\
2 & 27 & 28 & 40 & 67 \\
3 & 22 & 28 & 53 & 69 \\
4 & 26 & 33 & 65 & 66 \\
5 & 23 & 36 & 64 & 53 \\
6 & 27 & 40 & 62 & 43 \\
7 & 22 & 28 & 44 & 37 \\
\hline
\end{tabular}

uma consequência da alta variabilidade espacial da pastagem em condições de pastejo. Nos três primeiros ciclos, o crescimento das plantas foi influenciado, principalmente, pela incidência de radiação solar $(\mathrm{r}=0,73)$ (Tabela 2$)$, uma vez que não houve deficiência hídrica, e a temperatura do ar esteve próxima à faixa ótima para o crescimento de forrageiras tropicais (Figura 2) que, segundo Valente et al. (2011), é de 30 a $35^{\circ} \mathrm{C}$ para espécies $\mathrm{C}_{4}$.

Do $4^{\circ}$ ciclo em diante, as produtividades também não diferiram entre as posições, e não passaram dos $670 \mathrm{~kg} \mathrm{ha-1}$ de MS. Isso é uma indicação de que o sombreamento perdeu importância na determinação da produtividade, que passou a ser regulada pela deficiência hídrica e, em segundo plano, pela redução da temperatura do ar (Figura 2), que ficou próxima ao valor da temperatura base inferior da cultura, que é de aproximadamente $15^{\circ} \mathrm{C}$ para plantas $\mathrm{C}_{4}$ (Valente et al.,

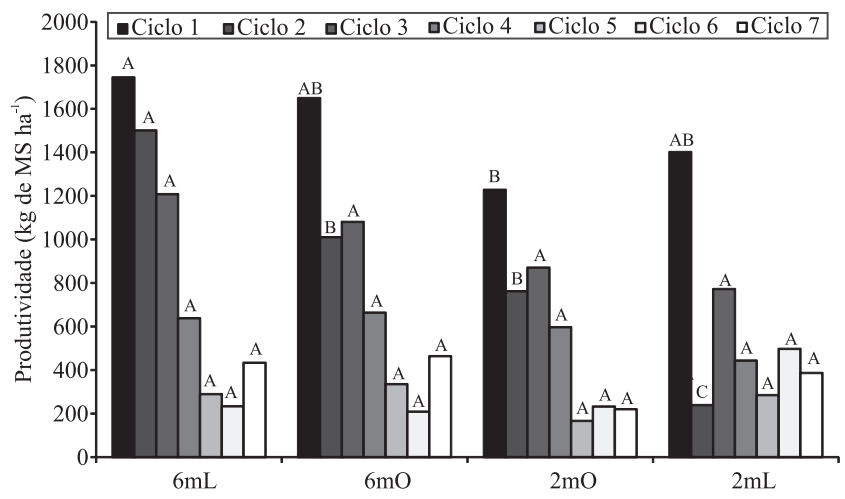

Figura 3. Produtividade de Urochloa decumbens de acordo com o ciclo de crescimento (duração de 35 dias), nas posições a $6 \mathrm{~m}$ do renque leste $(6 \mathrm{~mL})$, a $6 \mathrm{~m}$ do renque oeste $(6 \mathrm{mO})$, a $2 \mathrm{~m}$ do renque oeste $(2 \mathrm{mO})$ e a $2 \mathrm{~m}$ do renque leste $(2 \mathrm{~mL})$, em sistema silvipastoril. Médias seguidas por letras iguais não diferem entre si pelo teste Tukey, a 5\% de probabilidade, na comparação entre as posições dentro do mesmo ciclo.

Tabela 2. Coeficiente de correlação (r) entre as variáveis micrometeorológicas - radiação solar global (RS), temperatura média do ar (T) e deficiência hídrica acumulada (DEF) - com a produtividade de matéria seca (MS) e com as variáveis biométricas da pastagem - índice de área foliar (IAF), altura de planta, e área foliar específica (AFE) -, em sistema silvipastoril com Urochloa decumbens, durante as épocas seca e chuvosa.

\begin{tabular}{|c|c|c|c|c|c|c|c|c|c|c|c|c|}
\hline \multirow[t]{2}{*}{ Época } & \multicolumn{3}{|c|}{ Produtividade } & \multicolumn{3}{|c|}{ IAF } & \multicolumn{3}{|c|}{ Altura de planta } & \multicolumn{3}{|c|}{$\mathrm{AFE}$} \\
\hline & RS & $\mathrm{T}$ & DEF & $\mathrm{RS}$ & $\mathrm{T}$ & $\mathrm{DEF}$ & $\mathrm{RS}$ & $\mathrm{T}$ & DEF & $\mathrm{RS}$ & $\mathrm{T}$ & DEF \\
\hline Chuvosa & 0,73 & 0,66 & 0,30 & 0,56 & 0,13 & 0,43 & 0,68 & 0,86 & 0,22 & 0,74 & 0,45 & 0,68 \\
\hline Seca & 0,26 & 0,63 & 0,15 & 0,21 & 0,18 & 0,74 & 0,40 & 0,07 & 0,64 & 0,73 & 0,10 & 0,91 \\
\hline
\end{tabular}


2011). Abaixo desse valor, o crescimento das plantas é praticamente nulo, e em situações de suprimento de água inadequado, a tendência é de que as plantas fechem os estômatos, diminuindo as trocas gasosas e, consequentemente, a fotossíntese (Mendes et al., 2013). Gobbi et al. (2009) observaram que, em período seco, não houve diferença entre as produções de forragem de $U$. decumbens, nos níveis de 50 e $70 \%$ de sombreamento artificial e a pleno sol, o que corrobora os resultados do presente estudo.

Nos ciclos 2 e 3, o IAF (Figura 4), foi influenciado principalmente pela variação da incidência de radiação solar entre as distâncias (Figura 2), com coeficiente de correlação de 0,56 (Tabela 2). No ciclo 2, a posição $6 \mathrm{~mL}$ apresentou IAF maior do que as posições a $2 \mathrm{~m}$. O IAF da posição $6 \mathrm{mO}$ não diferiu estatisticamente dos valores obtidos nas demais posições. No ciclo 3, nas posições a $6 \mathrm{~m}$ do renque o IAF foi maior do que na posição a $2 \mathrm{~mL}$, mas não diferiram da posição $2 \mathrm{mO}$, o que indica que o sombreamento a partir de $40 \%$ reduziu o IAF. Resultado semelhante foi observado por Paciullo et al. (2007), que cultivaram $U$. decumbens a pleno sol e sob sombreamento natural de 35 e $60 \%$. Os autores constataram que o sombreamento mais intenso reduziu os valores de IAF, e observaram que as plantas sombreadas interceptaram praticamente a mesma quantidade de radiação que as a pleno sol, indício de que as plantas modificam a sua estrutura

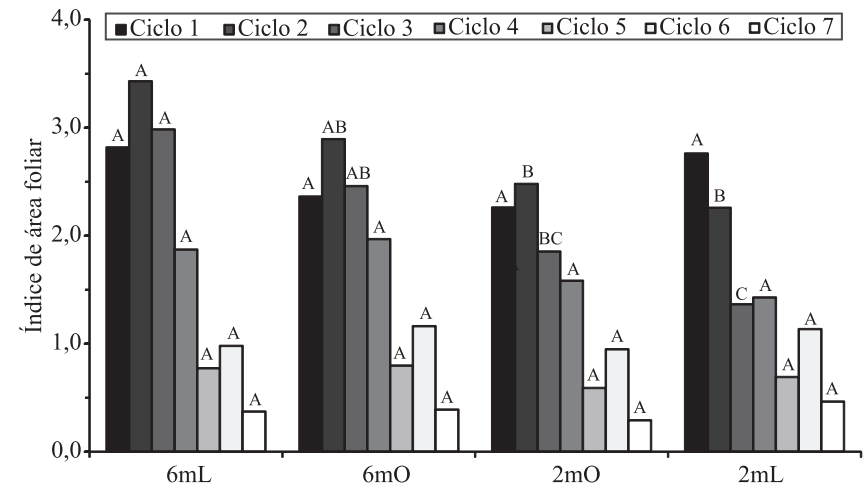

Figura 4. Índice de área foliar de Urochloa decumbens de acordo com o ciclo de crescimento (duração de 35 dias), nas posições a $6 \mathrm{~m}$ do renque leste $(6 \mathrm{~mL})$, a $6 \mathrm{~m}$ do renque oeste (6 $\mathrm{mO})$, a $2 \mathrm{~m}$ do renque oeste $(2 \mathrm{mO})$ e a $2 \mathrm{~m}$ do renque leste $(2 \mathrm{~mL})$, em sistema silvipastoril. Médias seguidas por letras iguais não diferem entre si pelo teste Tukey, a 5\% de probabilidade, na comparação entre as posições, dentro do mesmo ciclo. (ângulo foliar, disposição das folhas no dossel etc.) para aumentar a captação de luz, em detrimento do IAF.

A partir do ciclo 4, a exemplo do que ocorreu com a produtividade, não houve diferença do IAF entre as distâncias, uma vez que a deficiência hídrica e a baixa temperatura do ar (Figura 2) passaram a condicionar o IAF, que não ultrapassou 2,0 (Figura 4).

A altura de planta, nos quatro primeiros ciclos, foi influenciada pelo sombreamento (Figura 5), tendo apresentado coeficiente de correlação de 0,68 com a radiação solar incidente. Nos ciclos 1 e 2, a posição $2 \mathrm{~mL}$ foi a que apresentou as maiores alturas, com diferenças de $0,12 \mathrm{~m}$ e $0,09 \mathrm{~m}$, respectivamente, em comparação à posição $6 \mathrm{mO}$. Esse resultado pode ser atribuído ao alto nível de sombreamento na posição $2 \mathrm{~mL}$ (de 66 a 67\%), o que provocou o estiolamento das plantas. No ciclo 4, quando o aumento da declinação solar (movimento aparente do sol em direção ao Norte) diminuiu a incidência de luminosidade na posição $2 \mathrm{mO}$, as plantas das duas posições a $2 \mathrm{~m}$ das árvores atingiram maior altura do que as das posições a $6 \mathrm{~m}$. Isso pode ser explicado pelo alto nível de sombreamento nas distâncias a $2 \mathrm{~m}(53 \%$ a $2 \mathrm{mO}$ e $68 \%$ a $2 \mathrm{~mL})$, que provocou o estiolamento das plantas. Assim, podese inferir que sombreamento acima de $53 \%$ provoca o aumento da altura de planta de $U$. decumbens.

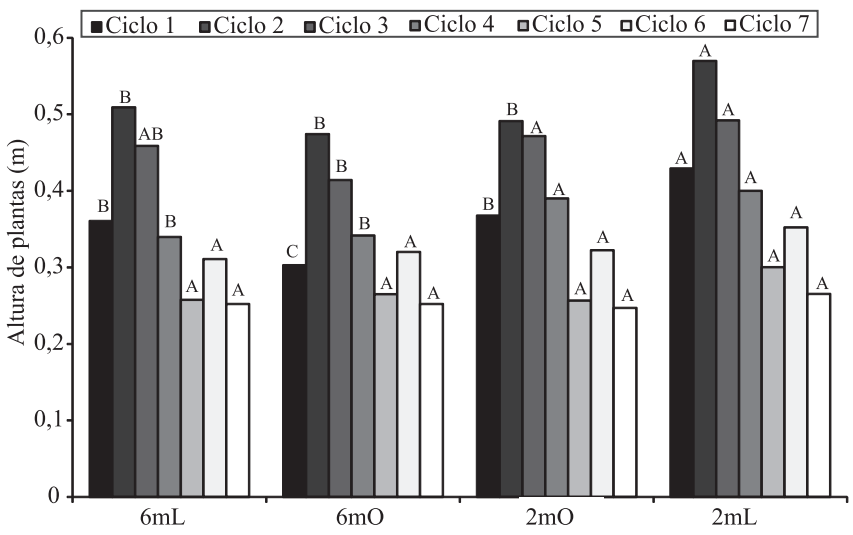

Figura 5. Altura de plantas de Urochloa decumbens de acordo com o ciclo de crescimento (duração de 35 dias), nas posições a $6 \mathrm{~m}$ do renque leste $(6 \mathrm{~mL})$, a $6 \mathrm{~m}$ do renque oeste (6 $\mathrm{mO})$, a $2 \mathrm{~m}$ do renque oeste $(2 \mathrm{mO})$ e a $2 \mathrm{~m}$ do renque leste $(2 \mathrm{~mL})$, em sistema silvipastoril. Médias seguidas por letras iguais não diferem entre si pelo teste Tukey, a 5\% de probabilidade, na comparação entre as posições, dentro do mesmo ciclo. 
Esses dados estão de acordo com os encontrados por Paciullo et al. (2008) e Martuscello et al. (2009), que constataram que, sob alto sombreamento, as plantas do capim-braquiária alongam seus colmos e folhas para aumentar sua exposição à radiação solar. Isso pode influenciar a produção de forragem, pois há maior utilização de fotoassimilados para o alongamento de colmos e folhas, em detrimento do acúmulo de MS.

A partir do ciclo 5, não houve mais influência do sombreamento sobre a altura das plantas, já que a deficiência hídrica e a baixa temperatura do ar passaram a limitar o crescimento da pastagem (Figura 2).

Nos três primeiros ciclos de rebrota, a AFE foi significativamente influenciada pelas distâncias (Figura 6). No ciclo 1, a posição $2 \mathrm{~mL}$ obteve maior AFE do que a posição $6 \mathrm{mO}$; porém, não diferiu das distâncias $6 \mathrm{~mL}$ e $2 \mathrm{mO}$. No ciclo 2, a posição $2 \mathrm{~mL}$ também apresentou AFE maior do que todas as outras. No ciclo 3, a AFE mais uma vez foi maior na posição $2 \mathrm{~mL}$ do que na posição $2 \mathrm{mO}$. Portanto, houve influência de sombreamentos superiores a $66 \%$ na alteração da dimensão das folhas, como estratégia das plantas de absorver maior quantidade de radiação solar pela maior área de sua superfície foliar. Carrilho et al. (2012) observaram que o capim-braquiária alonga suas folhas como forma de aumentar a exposição à luz, em ambientes com sombreamento artificial a

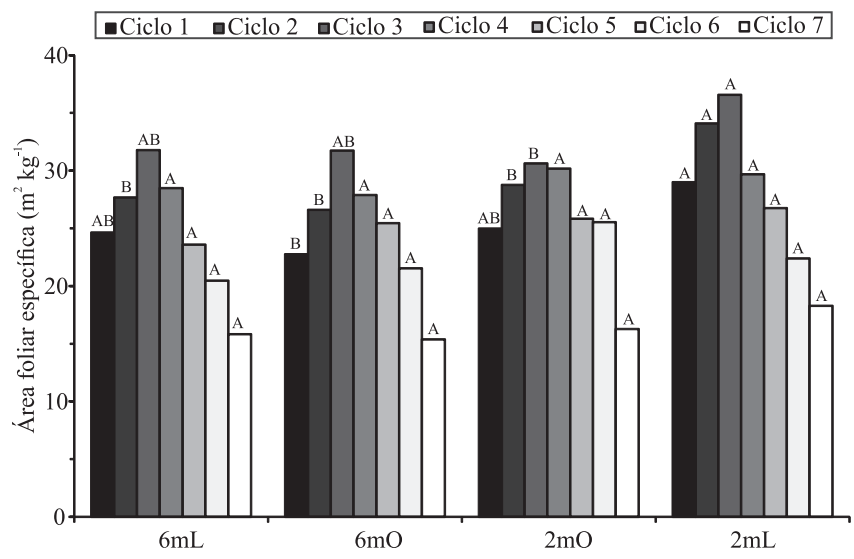

Figura 6. Área foliar específica de Urochloa decumbens de acordo com o ciclo de crescimento (duração de 35 dias), nas posições a $6 \mathrm{~m}$ do renque leste $(6 \mathrm{~mL})$, a $6 \mathrm{~m}$ do renque oeste (6 $\mathrm{mO})$, a $2 \mathrm{~m}$ do renque oeste $(2 \mathrm{mO})$ e a $2 \mathrm{~m}$ do renque leste $(2 \mathrm{~mL})$, em sistema silvipastoril. Médias seguidas por letras iguais não diferem entre si pelo teste Tukey, a 5\% de probabilidade, na comparação entre as posições, dentro do mesmo ciclo. partir de 50\%. Além disso, Garcez Neto et al. (2010) destacaram que a área, a espessura e o número de folhas, o comprimento do colmo e a relação folha/ colmo são variáveis que podem diminuir a quantidade e a qualidade da forragem.

Do ciclo 4 em diante, não houve diferenças significativas entre as posições do SSP quanto à AFE, que também foi condicionada pela limitação do crescimento das plantas, provocada pela deficiência hídrica, principalmente, e pela redução da temperatura. Isso confirma a baixa influência do sombreamento sobre a AFE, em situações em que ocorrem outros fatores ambientais limitantes.

\section{Conclusões}

1. O plantio de árvores nativas em renques, no sentido norte-sul, diminui a produtividade de forragem e o índice de área foliar e aumenta a altura de planta e a área foliar específica do capim-braquiária, nas distâncias de $2 \mathrm{~m}$ dos renques, nas épocas quentes e chuvosas.

2. A produtividade de forragem e as características biométricas do campim-braquiária não são afetadas pelo sombreamento das árvores nas épocas secas e frias, mas são determinadas pela deficiência hídrica e pela temperatura do ar.

\section{Agradecimentos}

À Embrapa Pecuária Sudeste, pelo apoio na fase experimental; à Coordenação de Aperfeiçoamento de Pessoal de Nível Superior (Capes), pela concessão de bolsa.

\section{Referências}

ALlEN, R.G.; PEREIRA, L.S.; RAES, D.; SMITH, M. Crop evapotranspiration: guidelines for computing crop water requirements. Roma: FAO, 1998. 300p. (FAO. Irrigation and drainage paper, 56).

BERNARDINO, F.S.; GARCIA, R. Sistemas silvipastoris. Pesquisa Florestal Brasileira, n.60, p.77-87, 2009.

CARRILHO, P.H.M.; ALONSO, J.; SANTOS, L.D.T.; SAMPAIO, R.A. Vegetative and reproductive behavior of Brachiaria decumbens cv. Basilisk under different shade levels. Cuban Journal of Agricultural Science, v.46, p.85-90, 2012.

DIAS-FILHO, M.B. Growth and biomass allocation of the $\mathrm{C}_{4}$ grasses Brachiaria brizantha and B. humidicola under shade. 
Pesquisa Agropecuária Brasileira, v.35, p.2335-2341, 2000. DOI: $10.1590 / \mathrm{S} 0100204 \mathrm{X} 2000001200003$.

DIAS, P.F.; SOUTO, S.M.; RESENDE, A.S.; URQUIAGA, S.; ROCHA, G.P.; MOREIRA, J.F.; FRANCO, A.A. Transferência do $\mathrm{N}$ fixado por leguminosas arbóreas para o capim Survenola crescido em consórcio. Ciência Rural, v.37, p.352-356, 2007. DOI: $10.1590 / \mathrm{S} 010384782007000200009$.

GARCEZ NETO, A.F.; GARCIA, R.; MOOT, D.J.; GOBBI, K.F. Aclimatação morfológica de forrageiras temperadas a padrões e níveis de sombreamento. Revista Brasileira de Zootecnia, v.39, p.42-50, 2010. DOI: 10.1590/S151635982010000100006.

GOBBI, K.F.; GARCIA, R.; GARCEZ NETO, A.F.; PEREIRA, O.G.; VENTRELLA, M.C.; ROCHA, G.C. Características morfológicas, estruturais e produtividade do capim-braquiária e do amendoim forrageiro submetidos ao sombreamento. Revista Brasileira de Zootecnia, v.38, p.1645-1654, 2009. DOI: 10.1590/ S151635982009000900002.

GÓMEZ, S.; GUENNI, O.; GUENNI, L.B. de. Growth, leaf photosynthesis and canopy light use efficiency under differing irradiance and soil $\mathrm{N}$ supplies in the forage grass Brachiaria decumbens Stapf. Grass and Forrage Science, v.68, p.395-407, 2013. DOI: $10.1111 /$ gfs. 12002 .

MARTUSCELLO, J.A.; JANK, L.; GONTIJO NETO, M.M.; LAURA, V.A; CUNHA, D. de N.F.V. da. Produção de gramíneas do gênero Brachiaria sob níveis de sombreamento. Revista Brasileira de Zootecnia, v.38, p.1183-1190, 2009. DOI: 10.1590/ S151635982009000700004.

MENDES, M.M. de S.; LACERDA, C.F. de; CAVALCANTE, A.C.R.; FERNANDES, F.É.P.; OLIVEIRA, T.S. de. Desenvolvimento do milho sob influência de árvores de paubranco em sistema agrossilvipastoril. Pesquisa Agropecuária Brasileira, v.48, p.1342-1350, 2013. DOI: 10.1590/ S0100204X2013001000005.

PACIULLO,D.S.C.;CAMPOS,N.R.;GOMIDE,C.A.M.;CASTRO, C.R.T. de; TAVELA, R.C.; ROSSIELLO, R.O.P. Crescimento de capim-braquiária influenciado pelo grau de sombreamento e pela estação do ano. Pesquisa Agropecuária Brasileira, v.43, p.917923, 2008. DOI: 10.1590/S0100204X2008000700017.

PACIULLO, D.S.C.; CARVALHO, C.A.B. de; AROEIRA, L.J.M.; MORENZ, M.J.F.; LOPES, F.C.F.; ROSSIELLO, R.O.P. Morfofisiologia e valor nutritivo do capim-braquiária sob sombreamento natural e a sol pleno. Pesquisa Agropecuária Brasileira, v.42, p.573-579, 2007. DOI: 10.1590/ S0100204X2007000400016.

PACIULLO, D.S.C.; GOMIDE, C.A.M.; CASTRO, C.R.T. de; FERNANDES, P.B.; MÜLLER, M.D.; PIRES, M. de F.Á.; FERNANDES, E.N.; XAVIER, D.F. Características produtivas e nutricionais do pasto em sistema agrossilvipastoril, conforme a distância das árvores. Pesquisa Agropecuária Brasileira, v.46, p.1176-1183, 2011. DOI: 10.1590/S0100204X2011001000009.

THORNTHWAITE, C.W.; MATHER, J.R. The water balance. Centerton: Drexel Institute of Technology, 1955. 104p.

VALENTE, T.N.P.; LIMA, E. da S.; HENRIQUES, L.T.; MACHADO NETO, O.R.; GOMES, D.Í.; SAMPAIO, C.B.; COSTA, V.A.C. Anatomia de plantas forrageiras e disponibilidade de nutrientes para ruminantes: revisão. Veterinária e Zootecnia, v.18, p.347-358, 2011.

ZANINE, A. de M. Resposta morfofisiológica em pasto sob pastejo. Colloquium Agrariae, v.1, p.50-59, 2005. DOI: 10.5747/ ca.2005.v01.n2.a014.

Recebido em 1ำ de dezembro de 2013 e aprovado em 12 de maio de 2014

Pesq. agropec. bras., Brasília, v.49, n.6, p.449-456, jun. 2014

DOI: $10.1590 / \mathrm{S} 0100-204 X 2014000600006$ 